\title{
CONEXÕES: TRANSFORMAÇÕES DO OBJETO DA ARTE
}

Ana Lúcia Mandelli de Marsillac e Edson Luiz André de Sousa

\author{
Ana Lúcia Mandelli \\ de Marsillac \\ Universidade \\ Federal de Santa \\ Catarina (UFSC), \\ Professora do \\ Programa de \\ Pós-Graduação \\ de Psicologia e \\ da Residência \\ Integrada \\ Multiprofissional \\ em Saúde \\ do Hospital \\ Universitário \\ (Rims/HU/UFSC), \\ Florianópolis/SC, \\ Brasil. \\ Edson Luiz André \\ de Sousa \\ Universidade \\ Federal do Rio \\ Grande do Sul \\ (UFRGS), Professor \\ do Programa de \\ Pós-Graduação \\ em Psicanálise: \\ Clínica e Cultura \\ e do Programa de \\ Pós-Graduação em \\ Psicologia Social e \\ Institucional, Porto \\ Alegre/RS, Brasil.
}

RESUMO: Este artigo é resultado de uma pesquisa de doutorado, envolvendo a temática da arte nos anos 70, nos contextos brasileiro e espanhol. Sustentada pela teoria e método da psicanálise, analisa obras de dois artistas brasileiros e de um grupo de artistas catalães. Reflete sobre as contingências de determinados atos de criação, bem como sobre os ideais utópicos que esses artistas colocaram em cena. Além disso, analisa que as transformações propiciadas pela arte contemporânea transformam a própria concepção de objeto de arte, aproximando-se do que em psicanálise denomina-se como objeto a.

Palavras-chave: arte; psicanálise; anos 70; objeto; utopia.

ABSTRACT: Connections: transformations of the art object. This article is the result of a doctoral research involving the theme of art in the 70s, the Brazilian and Spanish contexts. Supported by theory and method of psychoanalysis, analyzes works of two Brazilian artists and a group of Catalan artists. Reflects about the contingencies of certain acts of creation, as well as the utopian ideals that these artists put into play. It analyzes that the transformations brought about by contemporary art transform the concept of art object, approaching to what in psychoanalysis is called as object $a$.

Keywords: art; psychoanalysis; 70; object; utopia. 
A relação central de objeto, aquela que é dinamicamente criadora, é a da falta.

(Lacan, 1995, p. 51)

$\mathrm{D}$ e três percursos singulares e encantadores, organizamos estas possíveis conexões. Nesse texto, apresentamos e refletimos sobre uma obra de cada um dos artistas escolhidos: os brasileiros Cildo Meireles e Paulo Bruscky, e o coletivo catalão Grup de Treball. Em um recorte metodológico fixado nos anos 70, percorremos a obra desses artistas, relacionando-as aos seus contextos específicos e suas estratégias de criação e resistência aos contextos ditatoriais nos quais se encontravam. Essas obras aproximam-se por terem sido produzidas em contextos ditatoriais, mas, sobretudo, por manterem um foco conceitual, político e utópico semelhante.

De um olhar permeado pela psicanálise, pelos enigmas do inconsciente, surge esse encontro com a arte. Uma arte que se caracteriza pelo hibridismo e pela precariedade enquanto posicionamento crítico, político e utópico. Esses artistas, de forma singular, expuseram e compartilharam uma relação revigorada e, especialmente, política para com a vida e para com a própria arte.

Analisaremos que a arte contemporânea propõe uma modificação dos ideais do campo das artes, modificando, com isso, os objetos e as relações do campo com o seu contexto sócio-político-cultural. Os artistas escolhidos são grandes expoentes dessa arte e tiveram a força de expor posicionamentos exemplarmente críticos às questões internas e externas ao campo das artes. Trata-se de atitudes de resistência política e subjetiva ao que se impunha de forma violentamente homogeneizadora e de experimentações transgressoras às tradicionais regras do campo. Seus atos de criação revelam seus processos, suas buscas em transmitir mensagens e inquietações, e seus ideais de construção de coletivos. Esses artistas possibilitam aberturas utópicas, através dos jogos com os signos e com os meios. Seus atos são simbólicos, revelando a força de transformação, que a arte produz no laço social.

Nosso fio condutor será a concepção de objeto para a psicanálise, em especial a partir do seminário de Lacan, A relação de objeto (1957/1995), conectado às obras desses artistas. Buscamos analisar que a transformação dos paradigmas conceituais da arte está intrinsecamente atrelada à transformação da concepção de objeto. Estratégias de diferentes artistas aproximam-se, na medida em que se revê a relação entre arte e vida, sublinhando que a arte é um território de liberdades e, desta forma, pode instigar uma postura crítica no social. Objetos artísticos aproximam-se por não prezarem pela pureza da técnica, relacionando-se com outros saberes, mostrando-se em falta. É justamente a relação faltosa, incompleta, de encontro com os objetos que direciona a criação, tal como enfatiza Lacan (1995). 
Desde o início do século XX, verifica-se uma efervescência no campo das artes oposta aos ideais de pureza e linearidade estilística, tendendo a articular uma crítica a essas regras, bem como aos ditames institucionais e utopias de progresso. O futurismo que emergia na Itália, França e Rússia, bem como o dadaísmo, com sua antiarte, empenhavam-se em uma ruidosa batalha contra a arte tradicional. Através de provocações e desafios, buscavam instituir novas formas, atrair o público a participar de suas manifestações, recitais poéticos, performances e happenings, improvisados e espontâneos. Denunciavam o isolamento e a estagnação da arte, em movimentos compostos por músicos, poetas, pintores, pensadores e dramaturgos.

O artista Marcel Duchamp pode ser considerado o maior expoente deste movimento de crítica à arte tradicional. Suas obras foram a própria negação do moderno conceito de obra. Em oposicão aos ideais de progresso modernistas, Duchamp dá ênfase à lógica do retardamento, da desconstrucão, e à reflexão sobre as imagens. Sua influência artística estava antes de tudo em suas atitudes e nos seus ideais. Seu interesse não era plástico, mas crítico e filosófico (PAZ, 2008). Suas produções artísticas foram questionamentos aos valores vinculados à concepção de obra na época. Suas obras se materializavam em atos.

Entretanto, a distincão entre arte moderna e contemporânea só se fez clara em meados dos anos 1960 e 1970. Arthur Danto (2006), filósofo e crítico de arte, entende que este começo sem manifestos, sem slogans, sem muita consciência do que estava acontecendo, é próprio da contemporaneidade e, neste ponto, revela sua grande diferença com a modernidade. O contemporâneo se define, se seguirmos Giorgio Agamben, por uma singular relação com seu próprio tempo, ao qual sempre aderimos tomando distância. Neste ponto, ele sublinha, portanto, uma relação ao seu tempo inscrita por uma defasagem e anacronismo (AGAMBEN, 2008).

Talvez Marcel Duchamp tenha antevisto que os ideais são imateriais e iconoclastas, buscados por meio da arte, por meio da obra, mas sustentados em um mais além, lá onde a liberdade sinaliza. A liberdade foi conquistada através da recusa dos grilhões de uma história formalista, o que, entretanto, não indica uma negacão da história, mas a subversão de seus princípios.

Nos anos 70, artistas, tais como Cildo Meireles, Paulo Bruscky e o coletivo Grup de Treball, posicionaram-se criticamente e, até mesmo, arriscaram suas vidas em nome de um projeto maior. Suas obras, por mais ambientais, imateriais e precárias que sejam, têm o poder de expor o quanto o contexto da arte foi alterado. A arte buscava ampliar as questões exclusivas do seu campo, enfatizando a dimensão sócio-político-cultural de seus atos. 


\section{ENLACE}

Não se trata, em absoluto, do objeto considerado na teoria moderna como objeto plenamente satisfatório, o objeto típico, o objeto por excelência, o objeto harmonioso, o objeto que funda o homem numa realidade adequada [...] Freud nos indica que o objeto é apreendido pela via de uma busca do objeto perdido [...]. (LACAN, 1995, p. 13)

Ao referir-se ao objeto da teoria moderna, Jacques Lacan (1995) assinala uma lógica que pode permear a concepção de objeto. A hipótese de encontro com o objeto plenamente satisfatório foi sustentada por um ideal de completude e progresso. Se a modernidade colocou isto em evidência, ainda hoje esta lógica e os ideais que a sustentam fazem-se presentes. O que parece ser radicalmente diferente é a dimensão temporal. Hoje em dia, cada novo objeto se mostra capaz de satisfazer a falta. Acumulação do ter é associada a uma suposta completude do ser.

Entretanto, não se trata do objeto plenamente satisfatório, harmonioso, mas de uma inexorável falta constituinte dos objetos. De saber que tanto a psicanálise quanto a arte contemporânea levam a seu extremo. A experiência cotidiana nos mostra esse descompasso entre o que buscamos e o que encontramos nos objetos, hiância, mal-estar. A concepção de falta do objeto é aquilo que organiza o sujeito, que torna possível ser sujeito desejante. É a busca pelo objeto perdido que torna possível a redescoberta; significantes que deslizam na busca perpétua. Assim, tanto o ato analítico quanto o ato criativo buscam dar visibilidade ao vazio que suporta os objetos, revelam a incompletude constituinte dos objetos e a relação faltosa que os sujeitos estabelecem com eles. Esses campos produzem atos que rompem com os sentidos e com as estruturas lógico-discursivas, propiciando a criação de novos objetos.

O objeto ideal para a psicanálise é mítico, ainda que não possa ser encontrado; ele cumpre uma função. Cabe lembrar que o mito induz ao jogo de trocas significantes, inesgotável busca, ideal de esgotamento das trocas simbólicas. O mito do objeto ideal e sua busca cumprem uma função fundamental para o sujeito, pois instigam ao inesgotável desdobramento ficcional. A origem simbólica do universo natural é a função do mito.

O objeto ideal é suposto. Teria existido ao pequeno enfans em uma relação dual com a mãe na qual o bebê, supostamente, estaria, enquanto objeto ideal, capaz de completá-la. Momento fugaz que marca a trajetória subjetiva neurótica, pois, ao perceber que a mãe deseja outros objetos, começa sua busca pelo objeto capaz de completar este Outro primordial. Este desejo sustenta a dialética sujeito-objeto e inaugura a condição de sujeito. Sujeito barrado, diria Lacan (1995), por sua falta e incompletude, mas, sobretudo, sujeito desejante, uma vez que é essa 
inexorável condição faltante que o move a desejar. A barra é condição do sujeito que não se sustenta em uma suposta completude; isto seria a morte.

A busca da suposta satisfação passada, desta forma, orienta a escolha de objetos, orienta o olhar e a repetição. É o recorte que nos faz olhar e investir em alguns objetos e não em outros. Entretanto, como bem lembra Lacan (1995), tanto a busca quanto o encontro com o objeto têm sua apreensão subjetiva em um mais além. Essa assertiva sustenta-se justamente pela falta constituinte dos objetos e dos sujeitos. É pelo vazio apresentado pelo objeto que se torna possível ao sujeito confrontar-se com seus ideais que estão para além da materialidade do objeto. Busca incessante, repetição orientada pelo princípio do prazer, pelo apaziguamento da angústia ${ }^{1}$ frente ao vazio.

É nesta via que surge o conceito de objeto a (2005 e 1988), fundamental para a psicanálise e desenvolvido por Jacques Lacan. Objeto qualificado por um símbolo a que indica a palavra autre, outro, semelhante na sua alteridade radical, a fim de expressar a condição subjetiva desejante frente a uma ausência de resposta dos objetos. O objeto a indica a condição do objeto, enquanto causa do desejo, objeto furado que move o sujeito em busca de um ideal do qual não se tem plena consciência. Tensão e conflito estão presentes na relação sujeito-objeto, já que o que é buscado é obscuro, não se sabe exatamente o que é. O objeto a sublinha o traço de reconhecimento do sujeito em um mais além, em um desconhecimento constituinte, tanto no que se refere à sua origem quanto ao seu sentido. É vinculado ao Inconsciente, que move em uma direção, da qual não se tem pleno conhecimento: incompletude inexorável do saber, incessante busca.

O objeto a designa a impossibilidade do gozo, da completude. Objeto heterogêneo, escapa à lógica significante, de natureza Real. O objeto a é resto, é furo no Inconsciente, que constrói bordas. Sua força e organização atraem e animam os significantes. O furo é causa que incita a dar sentido, por sua vez, sempre parcial. Movimento tenso entre prazer e desprazer, move o desejo e faz deslizar os significantes.

Poderíamos aproximar o conceito de objeto a, lacaniano, ao de informe, proposto por Bataille, em 1929 (BATAILLE apud MORAES, 2005). Para o escritor, esse conceito serve para desclassificar, exigindo, como decorrência, que cada coisa tenha sua forma. O informe é como um escarro, não se assemelha a nada. "O informe é o trabalho da forma de dar a ver sua própria dessemelhança constitutiva” (ibidem, p. 112).

\footnotetext{
${ }^{1}$ Freud (1926) distingue a angústia em dois planos: a) Enquanto afeto originário, que se coloca entre sensação e sentimento numa reação à perda e à separação. A angústia, desta forma, apresentaria-se enquanto desamparo frente à perda do objeto. b) Enquanto sinal, é um afeto que sinaliza o perigo da castração.
} 
O objeto a, para Lacan (2005), também serve mais a desclassificar. Cabe sublinhar que tende a desclassificar o sujeito; leva-o a uma perturbação que pode vir a lhe restituir uma chance de enunciação, mesmo em estado de desespero. Nesse ponto, encontramos a ética da psicanálise.

O vazio do objeto não é reconfortante. Pelo contrário, desvela a angústia, que se busca constantemente apaziguar. Entretanto, segundo a psicanálise, não é mascarando a falta, que se prossegue. Supor o encontro com o objeto causa de desejo causa angústia, pois, segundo Lacan (2005), é nessa suposição de completude que haveria a suspensão do sujeito desejante, sujeito barrado, que se faz sujeito por sua incompletude. Nessa via, é preciso quebrar sentidos, desclassificar, resgatar o informe que sustenta as formas, pois é nesse confronto que se mostra o sujeito desejante; nesse ponto é que se torna possível a enunciação. A verdade do sujeito é extremamente singular e nebulosa, mas tem a força de restituir um lugar.

Cildo Meireles, Paulo Bruscky e o coletivo Grup de Treball são artistas que sustentaram a crítica ao objeto de arte ideal. Suas obras, de diferentes formas, conseguiram colocar em cena o vazio, desclassificar, esgarçar e esburacar os limites do campo, provocar reflexão contextual e ter implicações políticas. Nesta via, esses artistas indicam que o enlace entre sujeito-objeto não se dá na ilusão do objeto ideal e, sim, em um mais além que acena e desconcerta. A postura coerente com essa ética orienta seus atos de criação.

A perturbação da angústia produz sombras, indica sobras, convida a obras pois escancaram a função do objeto a que é, como lembra Lacan, o que resta de irredutível nesta operação total de surgimento do sujeito no lugar do Outro [...] A ligação entre angústia e objeto a é tão visceral que Lacan chega a propor pensar a angústia como "tradução subjetiva do objeto a" [...] Para situar a relevância desta discussão não podemos esquecer que o objeto a é uma espécie de dejeto, portanto, temos que pensá-lo sempre em queda, como o que "resiste a ser assimilado em uma função significante. Dejeto que resiste a 'significantização’ fundamento de todo sujeito do desejo”. (SOUSA, 2008, p. 21)

Considerando a teoria lacaniana (2005), o objeto a não vem apaziguar o sujeito, mas, sim, produzir angústia. Trata-se de um objeto em queda, dejeto que resiste a significação; trauma que se coloca à frente de seu tempo, irredutível ao campo da representação. Certamente, é possível analisar muitas das obras desses artistas pela via do objeto a. São obras que não apaziguam, que questionam o estatuto da imagem e, assim, o próprio sujeito, incitando à transformação. Entendemos que é neste ponto que ocorre o enlace entre o sujeito e suas obras, ainda que com nuances diferentes, uma vez que o ato de criação acontece a partir desse vazio 
que permeia os objetos e os sujeitos, vazio deslumbrante sempre a ser descoberto. As obras, enquanto objeto a/causa de desejo, determinam outras produções, enlaçando os sujeitos.

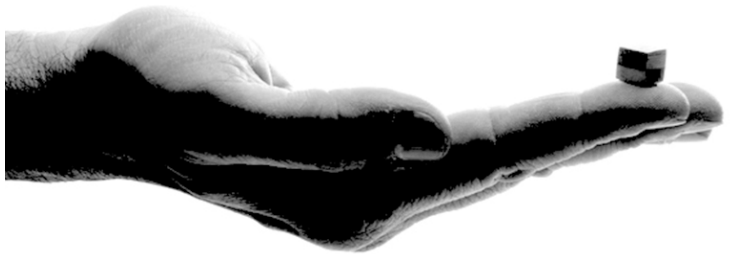

Imagem 1 - Cildo Meireles, Cruzeiro do Sul (1969-70)

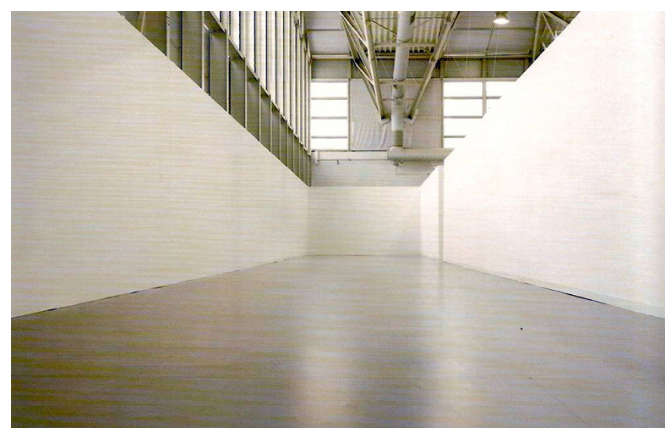

Imagem 1.1 - Cildo Meireles, Cruzeiro do Sul (1969-70)

Na obra Cruzeiro do Sul, de 1970, Cildo Meireles trabalha com a mitologia de origem do fogo para o povo indígena. Remete a um ponto de referência na imensidão da constelação, região mítica ao sul das Américas, inexistente nos mapas oficiais. Trata-se de um pequeno cubo de madeira, sendo uma seção de pinho e outra de carvalho, com dimensões de 9 x 9 x 9mm, disposto em uma sala com área mínima de $200 \mathrm{~m}^{2}$. Constitui-se como um ponto ínfimo na imensidão, compacto, mas, simbolicamente, imenso. Não somente por se referir a uma constelação estrelar que atesta a imensidão do universo e indica o sul do globo terrestre, mas pelo material do qual é composto: estas diferentes madeiras, quando postas em atrito, produzem o fogo. O saber indígena é sublinhado por Cildo Meireles através de seu ato.

Cruzeiro do Sul (imagem 1) é uma das obras de Cildo Meireles que possibilita a reflexão dessa dimensão do objeto a e sua relação com o sujeito. Pequeno cubo de madeira imerso na imensidão do "cubo branco"” que interroga, a um só tempo,

\footnotetext{
${ }^{2}$ Cubo branco é um termo utilizado pelo artista e crítico Brian D’Oherty como metáfora dos espaços da arte: museus e galerias. Espaços permeados por relações de poder e por certa sacralidade.
} 
sua condição de objeto e o sujeito que o olha. Ao entrar na sala, o sujeito talvez passe despercebido por aquele ínfimo objeto; sua condição não está dada por sua aparência. Trata-se de um objeto que questiona aquele que o olha por sua falta a ser. Para saber mais, é preciso sentir-se interrogado por ele. É preciso sentir-se, paradoxalmente, como ele, em falta e diametralmente oposto a ele, na suposta posição de completude subjetiva, posição defensiva do sujeito. É desse desconforto inicial que o sujeito pode ser remetido à sua história, ao seu processo de criação e aos seus ideais.

Trata-se, então, da queda da imagem que faz surgir o vazio, a imagem nua, despida de seu narcisismo. A partir da falha no imaginário elaboramos a idéia de lapso de imagem, como acontecimento psíquico que revela a estranheza inquietante do desejo inconsciente. (FRANÇA, 1997, p. XXIV)

Lapso de imagem é o conceito sugerido pela psicanalista Maria Inês França, remetendo ao sem sentido da imagem, ao desencontro entre aquilo que se espera e o que se olha. É ao romper com a suposta imagem ideal, dando a ver um objeto que não se sustenta apenas por sua presença e imagem, que precisa do simbólico para adquirir consistência, que o artista consegue produzir o efeito de lapso de imagem. Cildo Meireles expõe um objeto que, enquanto imagem e ínfima presença, desconcerta o sujeito, colocando o desejo em movimento.

O lapso de imagem é falha da miragem, efeito do inconsciente, tropeço no real, que movimenta o sujeito através do seu som angustiante e o recoloca enquanto desejante na busca incessante de significação, de novas inscrições e de novas apresentações do objeto de desejo. (FRANÇA, 1997, p. 85)

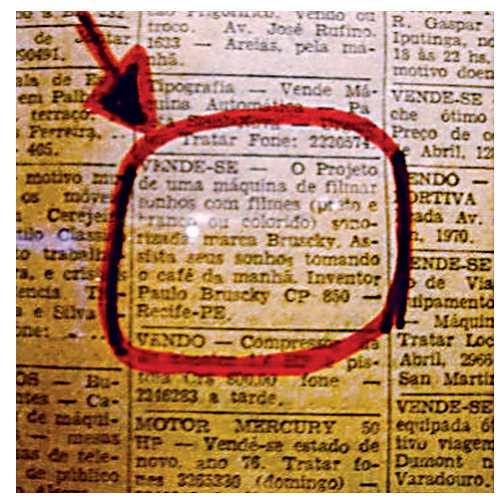

Imagem 2 - Paulo Bruscky, inserção em jornal, A máquina de filmar sonhos, 1977 


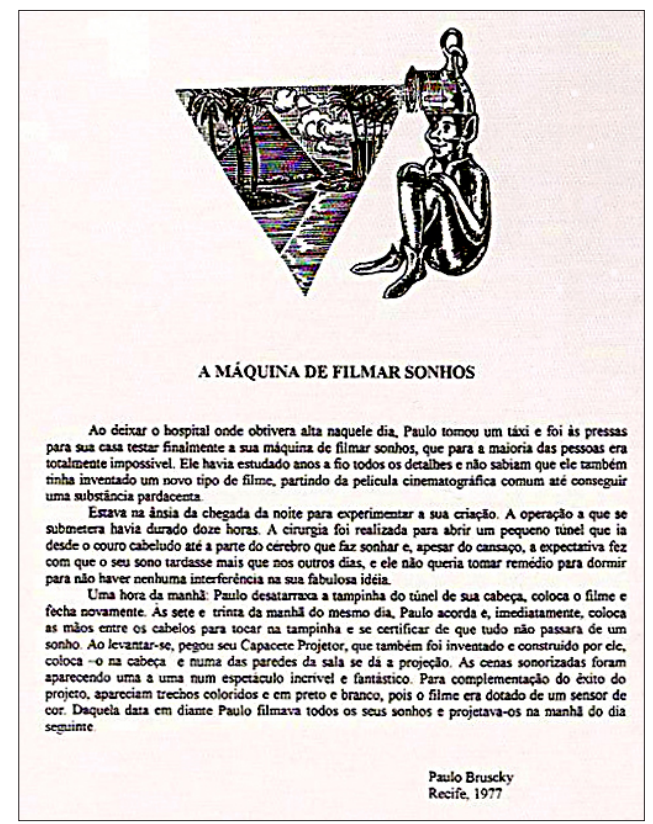

Imagem 2.1 - Paulo Bruscky, A máquina de filmar sonhos, 1977

Em um emblemático anúncio de jornal, em 1977, Paulo Bruscky vende o projeto de uma máquina de filmar sonhos (imagem 2), com filme, sonorizada, marca Bruscky. Além disso, o artista prometia ao comprador a oportunidade de ver seus sonhos no café da manhã! Atrelado ao anúncio, encontrava-se um conto sobre a surpreendente máquina que, se para muitos era totalmente inviável, para Paulo, munido de seu capacete projetor, tornara-se possível! A arte de Bruscky é a materialização de seus sonhos, desejava semear o sonho como forma de despertar.

A bem-humorada Máquina de filmar sonhos de Paulo Bruscky (imagem 2.1) se materializa pela via do desenho, mas também por sua descrição e "venda" através das inserções em jornais. Ela convoca o outro por sua falta a ser, pelo inusitado. Uma possível máquina de filmar sonhos seria maravilhosa ou insuportável? Será que conseguiríamos nos confrontar frequentemente com os desejos que os sonhos colocam em cena? Se rimos da inusitada proposta de Bruscky, é pelo impossível que coloca em jogo. Se nos esquecemos da maior parte dos nossos sonhos, é justamente porque eles trazem consigo a indizível angústia. Segundo Freud (1900/1988), o sonho é realização de desejo inconsciente. Desejo que parece torto à consciência, desejo do qual pouco se quer saber, uma vez que interroga profundamente a dimensão do sujeito. Paradoxal relação é estabelecida entre sonho e despertar, já que a força do hábito e da repetição tende a adormecer o sujeito. 
A máquina de Bruscky causa surpresa e estranhamento, potência criadora das rupturas que nos ajudam a despertar. O estranho, conforme as análises de Freud, em seu texto Das Unheimliche ${ }^{3}$, de 1919, parece-nos familiar e ao mesmo tempo inapreensível. O riso esconde a angústia frente ao que não se consegue imaginar. O lapso de imagem revela seus efeitos em um segundo tempo, "só depois", momento de abertura após o riso inicial. Bruscky sustenta a pergunta latente: o que se faz com os sonhos?

A estranheza inquietante fascina pela ausência de objetividade. Não é o objeto inquietante que desencadeia o fenômeno, é justo a queda do objeto diante dos próprios olhos que remete a uma experiência de indeterminação que representa, no campo do Outro, o traumático da constituição do sujeito. [...] na experiência Unheimliche o mundo objetivo desaparece. Isso vai implicar uma experiência subjetiva, a mais enigmática possível, onde domina a onipotência do pensamento. (FRANÇA, 1997, p. 77)

A máquina de filmar sonhos, de Bruscky, é antes de tudo impossível, revelando nossa condição inexorável de falta: queda do sujeito, encontro com aquilo que o ultrapassa, angustia. O estranho mundo dos sonhos nos habita e dele pouco conhecemos. A máquina de Bruscky faz desaparecer o mundo objetivo no jogo de objetivar aquilo que é impossível de ser objetivado. Trata-se de uma outra lógica, enigmática e indeterminada, que é governada pelo pensamento e pela liberdade que ele pode ter.

Champ d'attraction. Document. Travail d'information sur La presse illégale des Pays Catalans (imagem 3) foi o último trabalho que o Grup de Treball ${ }^{4}$ realizou, e o mais importante. Criado para exposição na $9^{a}$ Bienal de Paris, posteriormente também foi exposto, em 1976, na Bienal de Veneza e, em 1977, na Fundação Joan Miró, em Barcelona, na exposição Biennal de Venecia - Avantguarda Artística i Realisme Social a L'estat Espanyol, 1936-1976. Frente ao convite da Bienal de Paris, o grupo decidiu realizar uma obra interdisciplinar de grande impacto político. Entretanto, devido à Lei Antiterrorismo de agosto de 1975, e da implantação do estado de exceção e suas consequências repressivas, viram-se na necessidade de não assinar a obra. Tratava-se de uma oportunidade de difundir internacionalmente a existência e a evolução dos meios de comunicação fora do sistema (subversivos ao regime opressor), na Catalunha.

\footnotetext{
${ }^{3}$ O Estranho. É interessante, neste caso, resgatar o nome original em alemão, já que é a partir deste significante que Freud analisa a paradoxal relação entre familiar (Heimliche) e estranho (Unheimliche).

${ }^{4}$ O Grup de Treball teve uma curta existência (1973 a 1975).
} 


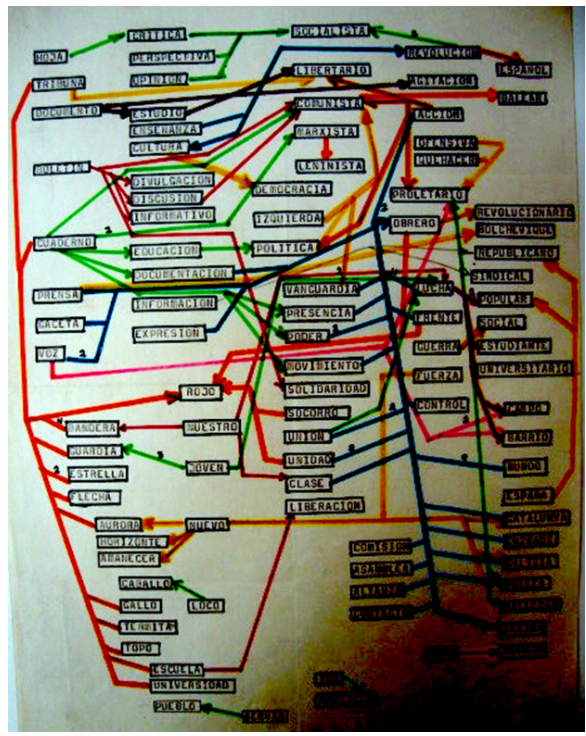

Imagem 3 - Grup de Treball, Champ d'attraction. Document. Travail d'information sur la presse illégale des Pays Catalans (Detalhe), 1975.

Foi realizado um trabalho de pesquisa sobre os principais jornais clandestinos, 115 no total, que circulavam na Catalunha durante o regime franquista, revelando a imprensa como meio de comunicação, veículo de ideologia, meio de informação, instrumento de agitação e organização. A materialização do projeto foi organizada para que se apresentassem alguns dos exemplares originais das publicações existentes, acompanhados de informações complementares, como um breve histórico de cada publicação. Também foi exposta uma lista com todas as publicações clandestinas existentes na Catalunha desde 1939. Posteriormente, foi realizado um campo de atração sintagmática com os nomes das principais publicações. Então, foi apresentado como obra final 11 plafons com reproduções fotográficas ampliadas de diferentes textos e estudos realizados, bem como fotogramas dos exemplares de jornais.

Como não assinaram a obra, o texto no catálogo da $9^{a}$ Bienal de Paris também não foi publicado, apresentando-se assim duas páginas em branco, que correspondem à participação do Grup de Treball. Um vazio não esperado, mas que tem a força de denunciar a opressão na qual viviam, reforçando o impacto da obra sobre a imprensa clandestina.

$\mathrm{Na}$ Bienal, foram lidos dois parágrafos de um comunicado que justificava as páginas em branco. Falam que a nova lei "antiterrorista” foi promulgada, visando frear a mínima abertura que existia e que se fazia visível na imprensa clandestina. Refletem que a imprensa foi a primeira a sofrer as conseqüências da nova lei e 
os setores intelectuais e artísticos também se viam reprimidos, temendo sofrer as pesadas penas que essa lei implicava. Isso justificou a ausência de assinatura e "inclusive impediu de levar a termo diversos aspectos deste trabalho, que se vê, portanto, mutilado” (MERCADER, 1999, p. 125).

Os artistas do Grup de Treball tornaram evidente o gatilho metodológico do qual se valiam em seu processo criativo. Afirmavam seu enlace por uma causa, enlace por uma luta de resistência. A obra que organizaram para a $9^{a}$ Bienal de Paris dá a ver que a luta política pela liberdade tem diferentes formas. É justamente a condição potente de enunciação, ainda que eminentemente faltosa, que os une e que faz laço com aquele que olha.

Eles abrem a cortina e mostram: muitos estão inconformados com este regime ditatorial. A censura se colocava como a cortina que velava uma luta e os seus ideais. Entretanto, cabe observar que é justamente esta cortina que os possibilitou eleger estes objetos que se constituem por esta interdição. É o véu que torna claro o desejo e a dimensão de um mais-além. Trata-se de um ressoar à distância, ato simbólico que indica outro significante que está mais longe da cadeia imediata, metonímia.

É uma maneira de falar de uma coisa inteiramente diversa, ao mesmo tempo implicando necessariamente, pela sequência rigorosa dos termos postos em jogo, uma contrapartida que é precisamente o que se quer fazer o outro escutar. Vocês vão encontrar aí o que eu chamei, [...] de metonímia, que consiste em dar a escutar alguma coisa falando de uma coisa completamente diferente. [...] Um romance que é feito de um punhado de pequenos traços sensíveis do real que nada querem dizer, não tem valor algum se não fizer vibrar harmonicamente um sentido mais além. (LACAN, 1995, p. 148)

A metonímia está presente na maioria das obras desses artistas, jogos com os significantes que indicam um mais além. O pequeno cubo de Cildo Meireles faz referência e questiona o campo da arte, os limites da escultura e seus significados. Remete ao fogo gerado pelo encontro dos diferentes tipos de madeira. Além disso, seu nome e pequeno formato designam a constelação estrelar e indicam uma determinada região do globo. Em um salto ainda maior, acena um ideal de liberdade de expressão, liberdade dos guetos oprimidos desde o "descobrimento" do Brasil. Utopia que é contida em um pequeno cubo. A máquina de Bruscky filma sonhos, grava aquilo que nos é nebuloso e indica, em um mais além, um ideal de que podemos dar mais valor aos nossos sonhos, que tornemos nossas faltas em potência criadora. Utopia que pode estar contida em um sonho.

O objeto não tem a capacidade de nos apresentar a falta, já que, como indica Lacan em seu seminário A angústia (2005), não há imagem da falta. O que 
percebemos através das obras desses artistas é que, ao darem a ver a precariedade das imagens em uma necessária referência ao simbólico, produzem um estranhamento desconfortante que move aquele que vê a buscar sentidos a estes objetos e suas imagens, que lhe escapam. Nesse gatilho, conduzem o sujeito a um mais além que indica um ideal. Ideal de liberdade que ganha forma em meio à interdição ditatorial, ideal evanescente que não se coloca a tamponar a falta, mas que cutuca o sujeito a despertar: aberturas utópicas.

\section{CONEXÕES UTÓPICAS}

Em um tempo em que supostamente temos a liberdade almejada, não se torna premente buscá-la. Será que despertamos ou, pelo contrário, estamos mais adormecidos? Resgatar a poética desses artistas é uma tentativa de despertar, sublinhando os descompassos entre o que se buscava nessa época e os desvios nos seus ideais. Nossos inimigos já não são tão claros, nossos desejos empobreceramse na falta de ideais.

Cildo Meireles, ainda que preze pela captura provocada pela imagem, vale-se da sua precariedade: imagens e objetos do cotidiano que montam uma cena, que buscam construir redes e levantam uma questão reflexiva. Paulo Bruscky rompe com o espaço tradicionalmente instituído para a arte, leva-a para a rua, convoca o outro a olhar e a estranhar o cotidiano. O coletivo Grup de Treball, ainda que extremamente ideológico e programático, construiu obras que negam os valores da arte tradicional e as imposições do governo ditatorial.

São artistas que, de diferentes formas, podem ser considerados utopistas iconoclastas ${ }^{5}$. Eles não criaram programas positivos, não sabiam a coisa certa a ser feita, mas sabiam exatamente contra o que deveriam lutar. Imaginaram outras realidades, outras possibilidades para a arte, nutrindo uma esperança utópica. Contestadores, desconstruíram imagens e ideais, revelando que a utopia precisa construir-se em oposição a algo, pois, sem um contexto claro ao qual se opor, os desejos utópicos parecem vagos. Criaram sonhos utópicos, que surgiram das realidades políticas e lançaram-se à liberdade do futuro. Entendemos que tornam claro que a utopia não requer apenas projetos, mas, fundamentalmente, direcionamentos éticos.

Precisamos pensar a utopia como interdição do presente, crítica ao que se coloca como verdade universal. A arte utópica se apresenta como não lugar. Ela coloca em cena o vazio, o mal estar de um tempo, sem, contudo, prever um paraíso a alcançar ou um lugar ideal. Seus atos de criacão fazem fenda, corte no

\footnotetext{
${ }^{5}$ Termo analisado pelo historiador Russel Jacoby, em sua obra Imagem Imperfeita: Pensamento Utópico para uma Época Antiutópica (2007).
} 
presente, revelando sua incompletude. Ideais que se constroem pela crítica ao seu tempo, resgatando traços do passado. Eles tiveram a força de mostrar que a arte é um território de liberdades. Suas obras revelam, dessa forma, utopias iconoclastas que recusam imagens ideais e ídolos a serem seguidos. Não se tratava mais de perseguir um estilo formal, mas de colocar a arte em re-conexão com a vida.

É fundamental observar que construíram ideais utópicos de forma singular e, exatamente por isso, permeadas por um coletivo. Esta parece ser outra das grandes diferenças entre esse tempo e a atualidade. Havia um ideal coletivo de liberdade, ainda que extremamente censurado. Expressão e união não poderiam ser presas, enclausuradas, no silenciamento da violência. Havia um clamor coletivo, ainda que muitas vezes velado. Suas obras parecem dar visibilidade a isso. Suas obras buscaram construir coletivos que se aproximavam por suas ideias e por suas esperanças.

Olhem! Escutem! Leiam! Estranhem aquilo que parece uniforme! Estas parecem ser consignas embutidas em suas obras. É possível perceber que recusaram o status do gênio criador; colocaram-se, muitas vezes, em segundo plano, a observar, a convidar à participação. Por se colocarem em falta, fizeram laços. Revelaram o poder do gueto, da crítica que não teme a tomada de posição. Nem tudo era possível, aliás, viviam cotidianamente em meio ao medo da violência que os sufocava.

A liberdade almejada não se afirmava naquela época, como erroneamente hoje se afirma, a um tudo pode. A leitura de suas obras nos mostra que não se tratava de experimentalismos sem direcionamentos éticos. Estes artistas tiveram e ainda têm extrema coerência em seus atos. A liberdade como exercício experimental da $\operatorname{rrte}^{6}$ parece significar uma multiplicidade de meios, multiplicidade de linguagens, que transmitem uma mensagem, que buscam compartilhar, fazer interlocução. A liberdade colocada em questão nesse despertar da arte contemporânea era uma liberdade construída através dos traços do passado, de uma crítica ao presente, para então acenar, em um mais além, um por vir. Suas obras nos mostram que, por trás da precariedade, encontra-se uma diversidade simbólica que tem a força de despertar. Abrir os olhos para as diferenças, para as formas de dizer, para os modos de construir coletivos. Esta é a política com direcionamento utópico.

“A utopia morre no empobrecimento dos desejos.” (JACOBY, 2007, p. 216)

Recebido em: 14 de dezembro de 2014. Aprovado em: 2 de junho de 2015.

\footnotetext{
6 "Liberdade como exercício experimental da arte" é uma frase utilizada por Paulo Bruscky em seus carimbos, possivelmente em referência à definição de arte proposta por Mário Pedrosa: arte como exercício experimental da liberdade.
} 


\section{REFERÊNCIĀS}

AGAMBEN, Giorgio. Qu'est-ce que le contemporain? Paris: Payot \& Rivages, 2008.

Catàleg de L’Exposició: “Grup de Treball”. Barcelona: MACBA, 1999.

Catálogo da Exposição: "Cildo Meireles”. Guy Brett (Ed.). Barcelona: MACBA, 2009.

Catálogo da Exposição: “Cildo Meireles, Geografia do Brasil”. Rio de Janeiro: Artviva Produção Cultural, 2001.

DANTO, Arthur. Após o fim da arte: a arte contemporânea e os limites da História. São Paulo: Odysseus, 2006.

FRANÇA, Maria Inês. Psicanálise, Estética e Ética do desejo. São Paulo: Perspectiva, 1997.

FREIRE, Cristina. Paulo Bruscky: arte, arquivo e utopia. São Paulo: Companhia Editora de Pernambuco, 2006.

Poéticas do Processo: arte conceitual no museu. São Paulo: Iluminuras, 1999.

FREUD, Sigmund. A Interpretação dos sonhos (1900). Rio de Janeiro: Imago, 1988.

Inibição, sintoma e angústia (1926). Rio de Janeiro: Imago, 1988.

. O Estranho (1919). Rio de Janeiro: Imago, 1988.

JACOBY, Russell. Imagem Imperfeita: pensamento utópico para uma época antiutópica. Rio de Janeiro: Civilização Brasileira, 2007.

LACAN, J. A angústia (1962-1963). Rio de Janeiro: J. Zahar, 2005. (O seminário, 10).

A relação de objeto. Rio de Janeiro: J. Zahar, 1995. (O seminário, 4).

Os quatro conceitos fundamentais da psicanálise. Rio de Janeiro: J. Zahar,

1988. (O seminário, 11).

MORAES, Marcelo J. Georges Bataille e as formações do abjeto. In: Outra Travessia. Florianópolis, 2005, n. 5.

O’DOHERTY, Brian. No interior do cubo: a ideologia do espaço da arte. São Paulo: Martins Fontes, 2002.

PAZ, Octavio. Marcel Duchamp, ou, O castelo da pureza. São Paulo: Perspectiva, 2008.

SOUSA, Edson L. A. A imagem perfeita. Revista da Associação Psicanalítica de Porto Alegre. Porto Alegre: APPOA, 2008, n. 34.

TEJO, Cristiana. Paulo Bruscky: arte em todos os sentidos. Pernambuco: CEPE, 2009.

Ana Lúcia Mandelli de Marsillac

ana.marsillac@ufsc.br

Edson Luiz André de Sousa

edsonlasousa@uol.com.br 
